\title{
Strategi Pengembangan UMKM Pangan Berdaya Saing di Kota Bandung
}

\author{
Developing Strategies of Competitive for Food Small Medium Enterprises In Bandung
}

Agustina Pertisia Ginting ${ }^{*}$, Musa Hubeis ${ }^{2}$, dan Farah Fahma ${ }^{2}$

${ }^{1}$ Mahasiswa Pascasarjana Program Studi Ilmu Manajemen IPB

${ }^{2}$ Departemen Manajemen, Fakultas Ekonomi dan Manajemen IPB

Jl. Kamper Kampus IPB Dramaga Bogor 16680

\begin{abstract}
ABSTRAK
UMKM (Usaha Mikro Kecil dan Menegah) merupakan salah satu sektor usaha yang memiliki peran penting dalam meningkatkan perekonomian di Indonesia. Salah satu UMKM yang memiliki potensi untuk berdaya saing adalah UMKM pangan. Untuk menciptakan UMKM pangan yang mampu bersaing dengan produk pangan lain maka harus mampu menjaga kualitas dari berbagai aspek. Banyaknya permasalahan yang dihadapi UMKM pangan maka dibutuhkan strategi agar dapat berkembang dan berkelajutan. Penelitian ini bertujuan untuk menciptakan kemampuan dan strategi daya saing pada UMKM pangan. Penelitian ini dilakukan dengan mengidentifikasi UMKM pangan, menganalisis pengaruh faktor internal dan faktor eksternal dengan matriks IE, mencari perumusan strategi UMKM pangan dengan metode SWOT dan QSPM. Lokasi penelitian dilakukan di Kota Bandung, Jawa Barat. Hasil dari penelitian berdasarkan matriks IE menunjukkan bahwa UMKM pangan Kota Bandung memerlukan strategi tumbuh dan membangun (grow and build). Berdasarkan metode SWOT dan QSPM didapatkan berbagai macam alternatif strategi. Strategi III menjadi strategi yang paling sesuai dengan UMKM pangan Kota Bandung dengan nilai 6,433. Strategi III yaitu "meningkatkan kemampuan SDM, memanfaatkan asosiasi dan dukungan pemerintah untuk memperluas pasar produk". Tingkat keberagaman UMKM pangan Kota bandung yang tinggi menjadikan karakteristik dari komoditas yang dihasilkan. Mayoritas pelaku usaha sangat mengandalkan pemerintah dalam semua aspek usaha. Pengadaan bahan baku dilakukan secara mandiri dengan sistem kontrak serta modal usaha sendiri.
\end{abstract}

Kata kunci: daya saing, pengembangan UMKM pangan, strategi

\begin{abstract}
SMEs (Micro-Small and Medium Enterprises) are one of business sector that has an important role for improving economy condition in Indonesia. One of the SMEs that has the potential to competition is food SMEs. To create food MSMEs that able to compete with the other food products, they must be able to maintain the quality of various aspects. The many problems faced by food SMEs require a strategy to develop and continue. This research aims to create competitiveness and strategy in food MSMEs. This research was conducted by identifying food MSMEs, analyse the influence of internal factors and external factors with the IE matrix, looking for the formulation of food SMEs strategies using SWOT and QSPM methods. The location of the research was conducted in the city of Bandung, West Java. The results of this research based on the IE matrix show that the Bandung City food UMKM requires a grow and build strategy. Based on the SWOT and QSPM methods, various alternative strategies were obtained. Strategy III is the most suitable strategy for Bandung's food UMKM with a value 6.433. Strategy III is "improving human resource capabilities, utilizing associations and government support to expand product markets". The level of diversity of food MSMEs in Bandung is high, that makes the characteristics of the commodities produced. The majority of business people rely heavily on the government in all aspects of business. Procurement of raw materials is carried out independently with a contract system and own business capital.
\end{abstract}

Key words: competitive, food SMEs development, strategy

\footnotetext{
*) Korespondensi:

Mahasiswa Pascasarjana Program Studi Ilmu Manajemen IPB; email: agustinapertisiaginting@gmail.com
} 


\section{PENDAHULUAN}

Usaha Mikro, Kecil dan Menengah (UMKM) menjadi bagian penting dari sistem perekonomian nasional yaitu mempercepat pemerataan partumbuhan ekonomi melalui penyediaan lapang usaha dan lapangan kerja, peningkatan pendapatan masyarakat, serta berperan dalam meningkatkan perolehan devisa dan memperkokoh struktur ekonomi nasional (Hubeis, 2009). Di Indonesia, jumlah UMKM lebih banyak dibandingkan dengan usaha-usaha berskala besar, sehingga UMKM menjadi sektor usaha yang paling mendominasi. Dalam hal in terdapat beberapa macam kelompok UMKM, salah satunya adalah UMKM Pangan. UMKM Pangan termasuk ke dalam sektor pertanian, peternakan, kehutanan dan perikanan; dan UMKM Pangan ini termasuk ke dalam subsektor tanaman bahan makanan. Menurut BPS (2006a) pada katalog 9102021 dan BPS (2006b) pada katalog 9102038, klasifikasi baku UMKM pangan di Indonesia meliputi restoran, warung makan, bar, kedai makanan dan minuman, penjual makanan dan minuman keliling dan jasa boga.

Kota Bandung merupakan salah satu kota di Jawa Barat yang memiliki potensi besar dalam pengembangan UMKM. Berkembangnya UMKM Pangan di kota Bandung kurang lebih sekitar tahun 2000, hal ini disebabkan perkembangan perekonomian di kota Bandung yang terus menunjukkan perkembangan setiap tahunnya. Rinciannya dapat dimuat pada Tabel 1.

Dilihat dari Tabel 1 dan 2, terlihat bahwa perkembangan jumlah UMKM yang terus mening- kat setiap tahun dengan tipe UMKM makanan dan minuman yang lebih banyak. Meningkatnya pengembangan UMKM Pangan, ada beragai permasalahan yang dihadapi.Menurut Winarni (2006) dan Situmorang (2008), permasalahan yang dihadapi oleh UMKM ialah (a) kurang permodalan, (b) kesulitan dalam pemasaran, (c) struktur organisasi sederhana dengan pembagian kerja yang tidak baku, (d) mutu manajemen rendah, (e) SDM terbatas dan mutunya rendah, (g) kebanyakan tidak mempunyai laporan keuangan, (h) aspek legalitas lemah dan (j) rendahnya mutu teknologi. Adapun jumlah UMKM binaan Dinas UMKM dan Perindustrian Perdagangan Kota Bandung 2015, dapat dilihat pada Tabel 2.

Melihat adanya berbagai permasalahan yang dihadapi UMKM Pangan dalam pengembangannya, dibutuhkan strategi bersaing. Hasil penelitian terdahulu Hubeis, et al. (2015), menunjukkan strategi untuk meningkatkan UMKM berdaya saing dilakukan dengan: (1) Meningkatkan kerjasama untuk menjaga kontinuitas ketersediaan bahan baku antar daerah; (2) membangun kawasan industri produk UMKM; (3) Meningkatkan peran pemerintah swasta dan perguruan tinggi/ penelitian pengembangan. Dengan jumlah yang banyak dan variasinya UMKM Pangan yang ada di Indonesia maka strategi yang dipakai tidak sama untuk setiap UMKM. Oleh karena itu, perlu kajian lanjut pada UMKM Pangan yang ada di kota Bandung untuk menghasilan UMKM berdaya saing.

Tabel 1. Jumlah UMKM Kota Bandung Tahun 2010-2015 (dalam unit)

\begin{tabular}{llrrrrrr}
\hline \multirow{2}{*}{ No } & \multirow{2}{*}{ Uraian } & \multicolumn{7}{c}{ Tahun } \\
\cline { 3 - 8 } & & 2010 & 2011 & 2012 & 2013 & 2014 & \multicolumn{1}{c}{2015} \\
\hline 1 & Mikro & 3.649 & 3.827 & 3.921 & 4.115 & 4.301 & 4.527 \\
2 & Kecil & 301 & 325 & 337 & 357 & 372 & 390 \\
3 & Menengah & 271 & 273 & 273 & 274 & 276 & 281 \\
\hline & Jumlah & 4.221 & 4.425 & 4.531 & 4.746 & 4.948 & 5.198 \\
\hline
\end{tabular}

Sumber: Dinas KUMKM dan Perindag Kota Bandung 2015.

Tabel 2. Jumlah UMKM berdasarkan tipe bisnis Tahun 2015 (dalam unit)

\begin{tabular}{clcccc}
\hline No. & Tipe Bisnis & Jumlah Mikro & Jumlah Kecil & Jumlah Menengah & Jumlah \\
\hline 1 & Fashion & 53 & 6 & 1 & 60 \\
2 & Makanan dan Minuman & 117 & 5 & - & 122 \\
3 & Kerajinan Tangan & 18 & 1 & - & 20 \\
4 & Jasa & 22 & 9 & 4 & 35 \\
5 & Perdagangan & 15 & 4 & - & 19 \\
\hline & JUMLAH UMKM & 225 & 25 & 5 & 255 \\
\hline
\end{tabular}

Sumber: Dinas KUMKM dan Perindag Kota Bandung 2015. 
Berdasarkan latar belakang yang telah dipaparkan, maka tujuan penelitian ini:

1. Mengidentifikasi karakteristik UMKM pangan di kota Bandung

2. Menganalisis pengaruh faktor internal dan faktor eksternal UMKM Pangan di kota Bandung untuk menciptakan UMKM Pangan Berdaya Saing.

3. Merumuskan strategi pengembangan UMKM Pangan berdaya saing di kota Bandung.

\section{METODE PENELITIAN}

Penelitian ini dilakukan pada bulan Juni sampai dengan November 2016 bertempat di Kota Bandung. Penelitian ini merupakan bagian dari penelitian berjudul Strategi Pengembangan UMKM Pangan yang Berdaya Saing di Indonesia.

Data yang digunakan dalam penelitian ini adalah data primer dan sekunder.Data primer adalah data yang diperoleh melalui hasil wawancara secara langsung dengan menggunaka kuesioner terhadap pihak-pihak yang terlibat dalam pengembangan UMKM Pangan. Data sekunder diperoleh dengan cara melakukan studi pustaka dari berbagai sumber yang tersedia.

Metode yang digunakan dalam penelitian ini adalah kuantitatif deskriptif dengan menggunakan wawancara semistruktur. Teknik pemilihan narasumber dalam penelitian ini dilakukan dengan menggunakan teknik purposive sampling, yaitu teknik penentuan sampel dengan pertimbangan tertentu (Sugiyono, 2013), melibatkan 30 responden
UMKM dan 5 responden pakar UMKM. Pengolahan dan analisis data terdiri dari analisis perumusan strategi yang terdiri dari analisis faktor internal dan eksternal, analisis matriks internal eksternal, analisis Strengths Weaknesses Opportunies Threats (SWOT) dan analisis Quantitative Strategic Planning Matrix (QSPM).

\section{HASIL DAN PEMBAHASAN}

\section{Karakteristik UMKM Pangan Berdaya Saing di Kota Bandung}

Berdasarkan hasil wawancara 30 UMKM di kota Bandung diperoleh hasil responden jenis kelamin perempuan lebih banyak dibandingkan dengan responden jenis kelamin laki-laki, 28 orang atau $93,33 \%$. Usia responden terbanyak 41-50 tahun sebanyak 14 orang $(46,7 \%)$, dengan rataan tingkat pendidikan Sekolah Menengah Atas (SMA). Omset penjualan UMKM Rp1.000.000-10.000.000 (66,67\%).

\section{Analisis Matriks IFE}

Hasil perhitungan matriks Internal Factor Evaluation (IFE) seperti dimuat pada Tabel 3, menunjukkan bahwa faktor kekuatan terbesar pada UMKM Pangan di kota Bandung adalah mutu produk telah sesuai harapan konsumen dengan skor 0,391. Mutu yang telah sesuai dengan harapan konsumen menunjukkan kepuasan konsumen terhadap UMKM. Faktor ini menjadi salah satu faktor kekuatan yang penting dalam pengembangan UMKM Pangan di kota Bandung dan harus dipertahankan.

Tabel 3. Hasil analisis Matriks IFE

\begin{tabular}{|c|c|c|c|c|}
\hline No. & Faktor-faktor internal & Bobot (a) & Rating (b) & Skor $(a x b)$ \\
\hline \multicolumn{5}{|c|}{ Kekuatan } \\
\hline 1 & Produk UMKM sangat beragam dan unik & 0,084 & 3,8 & 0,319 \\
\hline 2 & Menggunakan bahan baku bermutu & 0,096 & 4,0 & 0,384 \\
\hline 3 & Mutu produk telah sesuai harapan konsumen & 0,103 & 3,8 & 0,391 \\
\hline 4 & Memiliki sertfikat halal & 0,090 & 3,8 & 0,342 \\
\hline 5 & $\begin{array}{l}\text { Produksi UMKM telah memiliki kemasan dan label } \\
\text { sendiri }\end{array}$ & 0,094 & 3,8 & 0,357 \\
\hline 6 & $\begin{array}{l}\text { Menggunakan modal sendiri untuk produk yang } \\
\text { dihasilkan }\end{array}$ & 0,079 & 3,4 & 0,269 \\
\hline 7 & Harga produk terjangkau & 0,92 & 3,8 & 0,350 \\
\hline \multicolumn{5}{|c|}{ Kelemahan } \\
\hline 1 & Produk UMKM belum merupakan makanan khas & 0,077 & 1,8 & 0,139 \\
\hline 2 & Teknologi produksi yang digunakan masih sederhana & 0.095 & 1,6 & 0,152 \\
\hline 3 & Rendahnya ketersediaan tenaga kerja yang terampil & 0,100 & 1,4 & 0,140 \\
\hline \multirow[t]{2}{*}{4} & $\begin{array}{l}\text { Pemasaran produk UMKM berdasarkan mulut ke } \\
\text { mulut (kerabat) }\end{array}$ & 0,090 & 1,2 & 0,108 \\
\hline & TOTAL & 1,000 & 32,4 & 2,951 \\
\hline
\end{tabular}


Faktor kelemahan terbesar pada Tabel 3 adalah teknologi yang digunakan masih sederhana dengan skor 0,152. Dampak yang dapat diterima UMKM dengan penggunaan teknologi yang masih sederhana adalah proses produksi membutuhkan waktu panjang dan hasil produksi tidak banyak. Matriks IFE meringkas dan mengevaluasi kekuatan dan kelemahan utama dalam suatu usaha (David, 2006). Jumlah nilai bobot pada matriks IFE berkisar 1,0 yang rendah sampai 4,0 yang tinggi, dengan rataan 2,5. Pada Tabel 3, total bobot skor yang diperoleh 2,951, menunjukkan UMKM Pangan kota Bandung berada di posisi internal sedang mendekati kuat, yaitu dapat secara optimal menggunakan kekuatan yang dimiliki untuk mengatasi kelemahan yang dimiliki.

\section{Analisis Matriks EFE}

Tabel 4 hasil perhitungan matriks External Factor Evaluation (EFE), menunjukkan bahwa faktor peluang terbesar adalah meningkatnya pelanggan baru dan adanya loyalitas pelanggan dengan skor 0,551 . Menurut Swastha dalam Nurullaili dan Wijayanto (2013), definisi loyalitas pelanggan adalah kesetiaan konsumen untuk terus menggunakan produk yang sama dari suatu perusahaan.
Menurut Castro dan Armario dalam Beerli et al. (2004), loyalitas pelanggan tidak hanya meningkatkan nilai dalam bisnis, tetapi juga menarik pelanggan baru.

Faktor ancaman terbesar yang dapat dilihat pada Tabel 4 adalah fluktuasi harga bahan baku dengan skor 0,260. Biasanya hal ini terjadi pada UMKM dengan produksi bahan baku yang mengalami gagal panen akibat cuaca. Ancaman ini dapat menghambat proses produksi UMKM, sehingga UMKM harus memiliki cara untuk meminimalisir ancaman. Menurut David 2006, matriks EFE untuk merangkum dan mengevaluasi informasi ekonomi, sosial, budaya, demografi, lingkungan,politik, pemerintah, hokum, teknologi dan persaingan. Dalam matriks EFE, total nilai bobot tertinggi untuk suatu usaha adalah 4,0 dan terendah 1,0 dengan nilai skor rataan 2,5. Total bobot skor yang diperoleh dimuat pada Tabel 4, 3,197 menunjukkan UMKM Pangan kota Bandung berada di posisi eksternal tinggi, mengindikasikan bahwa UMKM merespon peluang dan ancaman dengan baik. Dengan kata lain, UMKM memanfaatkan peluang yang ada dan meminimalisir ancaman eksternal.

Tabel 4. Hasil analisis Matriks EFE

\begin{tabular}{|c|c|c|c|c|}
\hline No. & Faktor-faktor eksternal & Bobot (a) & Rating (b) & Skor $(a x b)$ \\
\hline \multicolumn{5}{|c|}{ Peluang } \\
\hline 1 & Terbukanya pasar ekspor dan domestik & 0,112 & 3,4 & 0,381 \\
\hline 2 & Adanya asosiasi kelompok usaha aktif & 0,107 & 3,6 & 0,385 \\
\hline 3 & $\begin{array}{l}\text { Mendapatkan dukungan dari pemerintah (berupa } \\
\text { perizinan, pelatihan, bazaar, dsb) }\end{array}$ & 0,116 & 3,8 & 0,441 \\
\hline 4 & $\begin{array}{l}\text { Meningkatnya pelanggan baru dan adanya loyalitas } \\
\text { pelanggan }\end{array}$ & 0,145 & 3,8 & 0,551 \\
\hline 5 & Mudah mendapatkan bahan baku yang digunakan & 0,138 & 3,6 & 0,497 \\
\hline 6 & Kemajuan teknologi & 0,127 & 3,8 & 0.483 \\
\hline \multicolumn{5}{|c|}{ Ancaman } \\
\hline 1 & Fluktuasi harga bahan baku & 0,130 & 2,0 & 0,260 \\
\hline \multirow[t]{2}{*}{2} & Tingkat persaingan dengan pelaku usaha sejenis & 0,125 & 1,6 & 0,200 \\
\hline & TOTAL & 1,000 & 25,6 & 3,197 \\
\hline
\end{tabular}

\begin{tabular}{|c|c|c|c|c|c|c|c|}
\hline & & & & Skor & Bobot Tot & IFE & \\
\hline & & & $\begin{array}{c}\text { Kuat } \\
\mathbf{3 , 0 - 4 , 0}\end{array}$ & & $\begin{array}{r}\text { Sedang } \\
2,0-2,99\end{array}$ & & $\begin{array}{l}\text { emah } \\
0-1,99\end{array}$ \\
\hline & & & & 3,0 & 2,951 & 2,0 & 1,0 \\
\hline$\because$ & Tinggi & 3,197 & (I) & & (II) & & (III) \\
\hline $\bar{\Xi}$ & $\begin{array}{c}\text { Sedang } \\
2,0-2,99\end{array}$ & 3,0 & (IV) & & (V) & & (VI) \\
\hline 产 & $\begin{array}{c}\text { Rendah } \\
1,0-1,99\end{array}$ & 1,0 & (VII) & & (VIII) & & (IX) \\
\hline
\end{tabular}

Gambar 1. Hasil Matriks IE 


\section{Analisis Matriks IE}

Matriks IE merupakan matriks yang menggabungkan bobot skor matriks IFE dan matriks EFE. Bobot skor matriks IFE 2,951 dan bobot skor matriks EFE 3,197. Hal ini menunjukkan posisi UMKM pangan berdaya saing di kota Bandung berada pada kuadran II (grow and build), yaitu posisi strategi pertumbuhan. yaitu posisi strategi pertumbuhan

\section{Analisis Matriks SWOT}

Setelah menganalisis matriks IFE dan EFE, maka dilanjutkan dengan matriks SWOT untuk merumuskan strategi-strategi berdasarkan faktor internal dan eksternal yang telah diidentifikasi dari UMKM pangan berdaya saing kota Bandung. Perumusan strategi dapat dilihat pada Tabel 5, dengan kombinasi faktor meliputi strategi SO, strategi ST, strategi WO dan strategi WT. Dari keseluruhan strategi yang diperoleh pada Tabel 6, strategi dengan nilai AS terbesar adalah S3, yaitu "meningkatkan kemampuan SDM, memanfaatkan asosiasi dan dukungan pemerintah untuk memperluas pasar produk" dengan nilai TAS 6,433 .

Tabel 5. Matriks SWOT UMKM Pangan di Kota Bandung

\begin{tabular}{|c|c|c|}
\hline External factor & $\begin{array}{l}\text { Strengths (S) } \\
\text { 1. Produk UMKM sangat } \\
\text { beragam dan unik } \\
\text { 2. Menggunakan bahan baku } \\
\text { bermutu } \\
\text { 3. Mutu produk telah sesuai } \\
\text { harapa konsumen } \\
\text { 4. Memiliki sertifikat halal } \\
\text { 5. Produk umkm telah memiliki } \\
\text { kemasan dan label sendiri } \\
\text { 6. Menggunakan modal sendiri } \\
\text { untuk produk yang dihasilkan } \\
\text { 7. Harga produk terjangkau }\end{array}$ & $\begin{array}{l}\text { Weaknesses (W) } \\
\text { 1. Produk UMKM belum merupakan } \\
\text { makanan khas } \\
\text { 2. Teknologi produksi yang } \\
\text { digunakan masih sederhana } \\
\text { 3. Rendahnya ketersediaan tenaga } \\
\text { kerja yang terampil } \\
\text { 4. Pemasaran produk UMKM } \\
\text { berdasarkan mulut ke mulut } \\
\text { (kerabat) }\end{array}$ \\
\hline $\begin{array}{l}\text { Opportunities (O) } \\
\text { 1. Terbukanya pasar ekspor dan } \\
\text { domestik } \\
\text { 2. Adanya asosiasi kelompok } \\
\text { usaha aktif } \\
\text { 3. Mendapatkan dukungan dari } \\
\text { pemerintah (berupa perizinan, } \\
\text { pelatihan, bazar, dll) } \\
\text { 4. Meningkatnya pelanggan baru } \\
\text { dan adanya loyalitas pelanggan } \\
\text { 5. Mudah mendapatkan bahan } \\
\text { baku yang digunakan } \\
\text { 6. Kemajuan teknologi }\end{array}$ & $\begin{array}{l}\text { Strategi S-O } \\
\text { 1. Meningkatkan mutu dan } \\
\text { variasi produk untuk menarik } \\
\text { minat pelanggan baru } \\
\text { 2. Menggunakan kemajuan } \\
\text { teknologi dan bahan baku } \\
\text { untuk meningkatkan produksi } \\
\text { serta memperluas pasar }\end{array}$ & $\begin{array}{l}\text { Strategi W-O } \\
\text { 1. Meningkatkan kemampuan SDM, } \\
\text { memanfaatkan asosiasi dan } \\
\text { dukungan pemerintah untuk } \\
\text { memperluas pasar produk } \\
\text { 2. Memaksimalkan bahan baku dan } \\
\text { kemampuan teknologi untuk } \\
\text { memproduksi produk UMKM } \\
\text { yang khas }\end{array}$ \\
\hline $\begin{array}{l}\text { Threats (T) } \\
\text { 1. Fluktuasi harga bahan baku } \\
\text { 2. Tingkat persaingan dengan } \\
\text { pelaku usaha sejenis }\end{array}$ & $\begin{array}{l}\quad \text { Strategi S-T } \\
\text { Menjaga mutu produk dan } \\
\text { mempertahankan nilai brand } \\
\text { untuk menghadapi persaingan } \\
\text { usaha sejenis }\end{array}$ & $\begin{array}{l}\quad \text { Strategi W-T } \\
\text { Mencari produsen untuk mencapai } \\
\text { kestabilan pasokan bahan baku dan } \\
\text { meningkatkan keterampilan SDM } \\
\text { sehingga dapat menciptakan UMKM } \\
\text { yang khas }\end{array}$ \\
\hline
\end{tabular}


Tabel 6. Matriks QSP UMKM Pangan di Kota Bandung

\begin{tabular}{|c|c|c|c|c|c|c|c|c|c|c|c|c|c|}
\hline \multirow{2}{*}{ Faktor kunci } & \multirow{2}{*}{ Bobot } & \multicolumn{2}{|c|}{ S1 } & \multicolumn{2}{|c|}{ S2 } & \multicolumn{2}{|c|}{ S3 } & \multicolumn{2}{|c|}{ S4 } & \multicolumn{2}{|c|}{ S5 } & \multicolumn{2}{|c|}{ S6 } \\
\hline & & AS & TAS & AS & TAS & AS & TAS & AS & TAS & AS & TAS & AS & TAS \\
\hline \multicolumn{14}{|l|}{ KEKUATAN } \\
\hline $\begin{array}{l}\text { a. Produk UMKM sangat } \\
\text { beragam dan unik }\end{array}$ & 0,084 & 4 & 0,336 & 4 & 0,336 & 0,336 & 0,336 & 3,8 & 0,319 & 3,8 & 0,319 & 4 & 0,336 \\
\hline $\begin{array}{l}\text { b. Menggunakan bahan baku } \\
\text { bermutu }\end{array}$ & 0,96 & 3,6 & 0,346 & 4 & 0,384 & 3,6 & 0,346 & 4 & 0,384 & 3,8 & 0,365 & 3,8 & 0,365 \\
\hline $\begin{array}{l}\text { c. Mutu produk telah sesuai } \\
\text { harapa konsumen }\end{array}$ & 0,103 & 3,6 & 0,371 & 3,8 & 0,391 & 3,8 & 0,391 & 3,6 & 0,371 & 3,8 & 0,391 & 3,8 & 0,391 \\
\hline d. Memiliki sertifikat halal & 0,090 & 4 & 0,360 & 4 & 0,360 & 4 & 0,360 & 4 & 0,360 & 4 & 0,360 & 4 & 0,360 \\
\hline $\begin{array}{l}\text { e. Produk UMKM telah } \\
\text { memiliki kemasan dan label } \\
\text { sendiri }\end{array}$ & 0,094 & 3,4 & 0,320 & 3,8 & 0,357 & 4 & 0,376 & 3,8 & 0,357 & 4 & 0,376 & 4 & 0,376 \\
\hline $\begin{array}{l}\text { f. Menggunakan modal sendiri } \\
\text { untuk produk yang } \\
\text { dihasilkan }\end{array}$ & 0,079 & 3,2 & 0,253 & 3,2 & 0,253 & 3,6 & 0,284 & 3,4 & 0,269 & 3,4 & 0269 & 3,6 & 0,284 \\
\hline g. Harga produk terjangkau & 0,092 & 3,8 & 0,350 & 3,6 & 0,331 & 3,8 & 0,350 & 3,8 & 0,350 & 3,8 & 0,350 & 3,8 & 0,350 \\
\hline \multicolumn{14}{|l|}{ KELEMAHAN } \\
\hline $\begin{array}{l}\text { h. Produk UMKM belum } \\
\text { merupakan makanan khas }\end{array}$ & 0,077 & 1,8 & 0,139 & 1,8 & 0,139 & 1,6 & 0,123 & 1,8 & 0,139 & 1,6 & 0,123 & 1,4 & 0,108 \\
\hline $\begin{array}{l}\text { i. Teknologi produksi yang } \\
\text { digunakan masih sederhana }\end{array}$ & 0,095 & 1,8 & 0,17 & 1,6 & 0,152 & 1,6 & 0,152 & 1,8 & 0,171 & 1,6 & 0,152 & 1,8 & 0,171 \\
\hline $\begin{array}{l}\text { j. Rendahnya ketersediaan } \\
\text { tenaga kerja yang terampil }\end{array}$ & 0,100 & 2 & 0,200 & 2 & 0,200 & 2 & 0,200 & 2 & 0,200 & 2 & 0,200 & 2 & 0,200 \\
\hline $\begin{array}{l}\text { k. Pemasaran produk UMKM } \\
\text { berdasarkan mulut ke mulut } \\
\text { (kerabat) }\end{array}$ & 0,090 & 1,8 & 0,162 & 1,8 & 0,162 & 1,6 & 0,144 & 1,8 & 0,162 & 1,6 & 0,144 & 1,4 & 0,126 \\
\hline \multicolumn{14}{|l|}{ PELUANG } \\
\hline $\begin{array}{l}\text { a. Terbukanya pasar ekspor } \\
\text { dan domestik }\end{array}$ & 0,112 & 3,6 & 0,403 & 3,8 & 0,426 & 3,8 & 0,426 & 3,8 & 0,441 & 3,8 & 0,426 & 3,6 & 0,403 \\
\hline $\begin{array}{l}\text { b. Adanya asosiasi kelompok } \\
\text { usaha aktif }\end{array}$ & 0,107 & 3,6 & 0,385 & 3,8 & 0,385 & 3,8 & 0,407 & 3,4 & 0,364 & 3,6 & 0,385 & 3,8 & 0,407 \\
\hline $\begin{array}{l}\text { c. Mendapatkan dukungan dari } \\
\text { pemerintah (berupa } \\
\text { perizinan, pelatiha, bazar, dll) }\end{array}$ & 0,116 & 3,6 & 0,418 & 3,8 & 0,441 & 3,8 & 0,441 & 4 & 0,464 & 4 & 0,464 & 4 & 0,464 \\
\hline $\begin{array}{l}\text { d. Meningkatnya pelanggan } \\
\text { baru dan adanya loyalitas } \\
\text { pelanggan }\end{array}$ & 0,145 & 3,8 & 0,551 & 4 & 0,580 & 4 & 0,580 & 3,8 & 0,551 & 3,8 & 0,551 & 4 & 0,58 \\
\hline $\begin{array}{l}\text { e. Mudah mendapatkan bahan } \\
\text { baku yang digunakan }\end{array}$ & 0,138 & 3,8 & 0,524 & 3,4 & 0,469 & 4 & 0,552 & 3,8 & 0,524 & 3,8 & 0,524 & 4 & 0,580 \\
\hline f. Kemajuan teknologi & 0,127 & 3,8 & 0,483 & 4 & 0,508 & 4 & 0,508 & 3,8 & 0,524 & 3,8 & 0,483 & 3,8 & 0,483 \\
\hline \multicolumn{14}{|l|}{ ANCAMAN } \\
\hline g. Fluktuasi harga bahan baku & 0,130 & 2 & 0,260 & 2 & 0,260 & 1,6 & 0,208 & 1,8 & 0,234 & 1,8 & 0,234 & 1,4 & 0,182 \\
\hline $\begin{array}{l}\text { h. Tingkat persaingan dengan } \\
\text { pelaku usaha sejenis }\end{array}$ & 0,125 & 1,6 & 0,200 & 1,6 & 0,200 & 2 & 0,250 & 1,8 & 0,225 & 1,8 & 0,225 & 2 & 0,250 \\
\hline
\end{tabular}

Kesiapan lima IKM dalam menerapkan SNI 2973:2011 secara berturut-turut sebagai berikut IKM A sebesar 97,4\%; IKM B sebesar 84,5\%; IKM C sebesar 83,6\%; IKM D sebesar $62,9 \%$; dan IKM E sebesar 71,4\%. Hasil pengelompokan kelima IKM diperoleh empat.

\section{Implikasi Manajerial}

Hasil penelitian implikasi manajerial yang dapat dilakukan adalah dengan menggunakan dan memanfaatkan kekuatan dan peluang yang dimiliki UMKM Pangan, serta mengatasi kelemahan dan ancaman yang terdapat pada bagian internal dan ekternal UMKM Pangan Kota Bandung.
Dari pembuatan matriks SWOT dan QSPM didapatkan beberapa strategi terkait pada mutu, teknologi, keterampilan SDM dan keterkaitan dengan pemasok. Pada hasil QSPM, kekuatan lebih diarahkan kepada mutu, bahan baku, sertifikat dan kemasan. Disamping memiliki peluang adanya pelanggan baru, kemajuan teknologi dan kemudahan mendapatkan bahan baku. Pengembangan UMKM Pangan di Kota Bandung, erat kaitannya dengan manajemen produksi dan operasi yang diikuti dukungan manajemen pemasaran untuk memperluas pasar. 


\section{KESIMPULAN}

UMKM Pangan Kota Bandung memiliki karakteristik produk yang dihasilkan sangat beragam. Keberagaman produk yang dihasilkan menjadi daya tarik pelanggan untuk menikmati UMKM Pangan dan keberagaman ini menjadikan ciri khas UMKM Pangan Kota Bandung.

Dari hasil analisis faktor internal dan eksternal yang diperoleh, dengan meningkatnya UMKM Pangan di kota Bandung harus selalu memperhatikan mutu bahan baku agar mutu produk dapat selalu sesuai dengan harapan pelanggan, baik pelanggan baru maupun pelanggan yang loyal. Dukungan dari pemerintah yang sangat aktif terhadap pengembangan UMKM Pangan kota Bandung agar mampu berdaya saing harus dimanfaatkan dengan maksimal, karena sangat dapat membantu UMKM, terutama UMKM yang baru. Untuk itu diperlukan strategi terkait produksi khususnya mutu dan teknologi disertai kemampuan SDM.

\section{DAFTAR PUSTAKA}

Beerli, A., J.D. Martin, \& A. Quintana. 2004. A Model of Customer Loyality in The Retail Banking Market. European Journal of Marketing. 38.

[BPS] Badan Pusat Statistik. 2006a. Perusahaan Mikro dan Kecil Penyediaan Makan dan Minum Hasil Sensus Ekonomi 2006. BPS Katalog 9102021. Jakarta (ID): Badan Pusat Statistik.
[BPS] Badan Pusat Statistik. 2006b. Perusahaan Menengah dan Besar Penyediaan Makan dan Minum Hasil Sensus Ekonomi 2006. BPS Katalog 9102038. Jakarta (ID): Badan Pusat Statistik.

David, F.R. 2006. Manajemen Strategi (Terjemahan). Jakarta (ID). Salemba Empat.

Dinas KUKM Kota Bandung. 2015. Katalog UMKM Kota Bandung. Bandung (ID): Dinas Koperasi, UKM dan Perdagangan dan Perindustrian Kota Bandung.

Hubeis, M. 2009. Prospek Usaha Kecil dalam Wadah Inkubator Bisnis. Bogor (ID): Ghalia Indonesia

Hubeis, M. 2015. Strategi Pengembangan UMKM Pangan Berdaya Saing di Indonesia. Riset tahun 1. Bogor (ID): FEM IPB

Nurullaili dan A. Wijayanto. 2013. Analisis Faktor-Faktor yang Mempengaruhi Loyalitas Konsumen Tupperware. Administrasi Bisnis. 2(1): 89-97

Situmorang, J. 2008. Strategi UMKM dalam Menghadapi Iklim Usaha yang Tidak Kondusif.Infokop. 16:88-101.

Sugiyono. 2013. Metode Penelitian Kombinasi (Mixed Methods). Bandung (ID): Alfabeta.

Winarni, E.S. 2006. Strategi Pengembangan Usaha Kecil melalui Peningkatan Aksesibilitas Kredit Perbankan. Infokop, 29(22). 